\title{
Article
}

\section{Bioseparation of Lectin by Dextran Produced by Dextransucrase}

\author{
Hidetaka Kawakita*, Kohshi Hamamoto, Hirokazu Seto, Keisuke Ohto, \\ Hiroyuki Harada, Katsutoshi Inoue \\ Department of Applied Chemistry, Saga University, 1- Honjo, Saga 840-8502, Japan
}

(Manuscript submitted March 30, 2007; accepted May 15, 2007)

\begin{abstract}
Dextransucrase (DSase) forms a complex with dextran during reaction with sucrose as a substrate. Dextransucrase-containing solution was permeated through the inorganic membrane of Shirasu Porous Glass to immobilize the enzyme on the pore surface. Sucrose solution $(25 \mathrm{~g} / \mathrm{L})$ was again permeated through the dextransucrase-immobilized membrane, producing the dextran throughout the pore at the range to $15 \mathrm{mg} / \mathrm{g}$. Concanavalin A extracted from jack bean was adsorbed to the produced dextran in permeation mode. Concanavalin A adsorption was evaluated by changing the amount of produced dextran and the residence time of concanavalin $\mathrm{A}$ in the membrane.
\end{abstract}

Key words: dextranscurase, dextran, concanavalin A, adsorption, membrane

\section{Introduction}

Dextransucrase (DSase) produces dextran as the main product, and fructose as a by-product, from a sucrose substrate [1]. Dextran forms a complex with DSase at the active site of DSase via a covalent-like bond. Dextran is a polysaccharide with an $\alpha-(1,6)$ pyranose ring linkage and has the following unique characteristics; 1$)$ flexibility of the random structure, 2) high solubility due to the hydroxyl group, and 3) high stability. When using dextran for molecular immobilization, its flexible structure is useful in maintaining the structure and activity of the molecule during immobilization. The hydrophilicity of the dextran attached to the surface inhibits unexpected molecular adhesion. Dextran has been used for a blood volume expander [2] and as a gel for gel permeation chromatography [3].

A conventional bioseparation material made of dextran is Sephadex, a dextran gel, in which high-molecular weight dextran is chemically cross-linked with epichlorohydrin [4]. However, Sephadex gel swells in water, demonstrating that the gel does not have mechanical strength. To utilize the unique character of dextran as a gel, dextran should be immobilized to a material surface, to obtain a synergistic effect between the hydrophilic character of dextran and the strength of the trunk material.

In this study, immobilized DSase on pore surfaces formed dextran at the active sites by reacting with sucrose to use for concanavalin A (Con A) adsorption. There are many papers on chemical modification of surfaces with dextran $[5,6]$. However, the excluded volume of functional dextran inhibits smart immobilization due to steric hindrance. Attachment of dextran by immobilized DSase would allow effective control of the dextran density and length. Con A is a lectin which has affinity for polysaccharides, mannose and glucose, and is frequently utilized as a model for polysaccharide-protein interactions [7]. The recognition site of Con A is the hydroxyl 

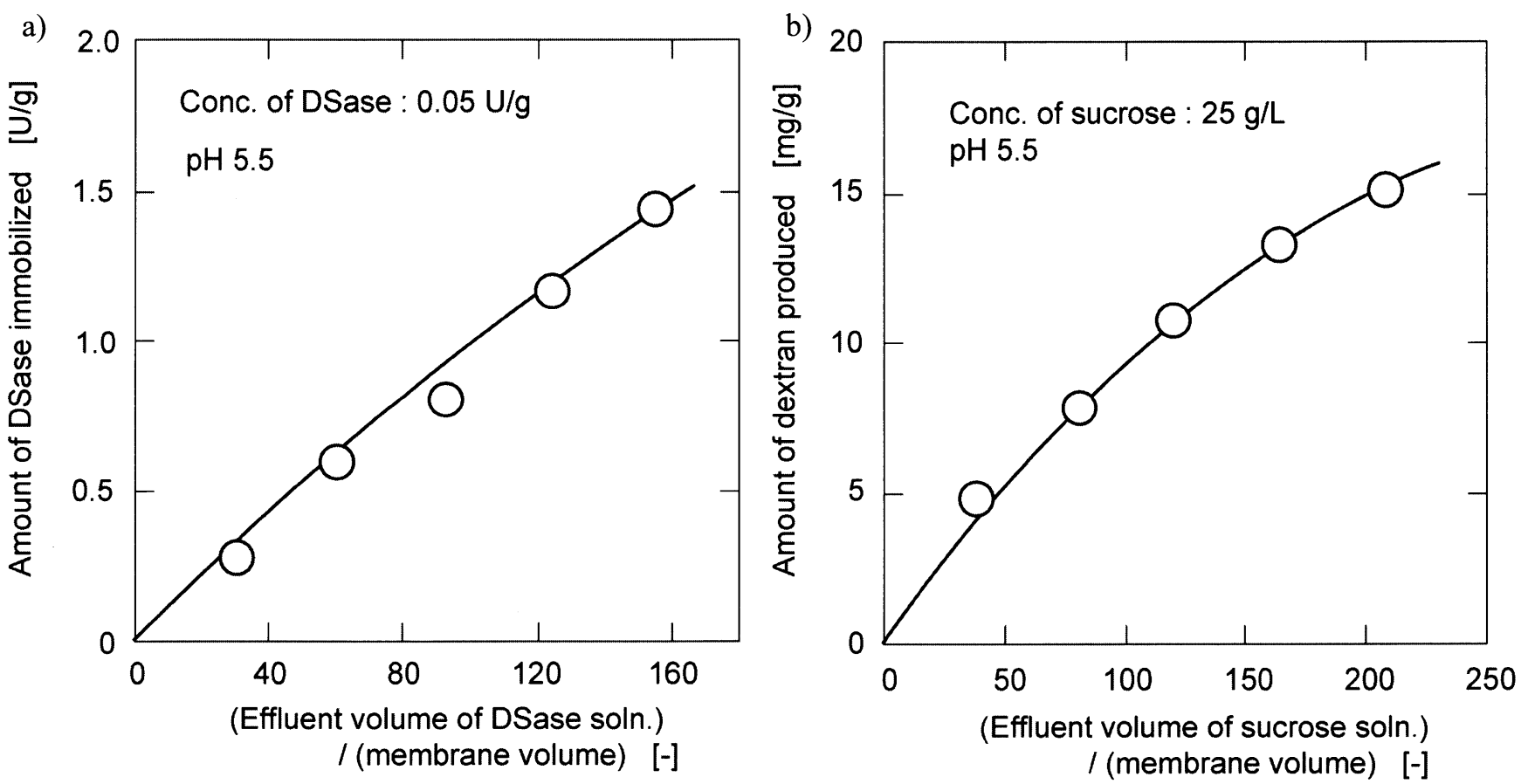

Fig. 1 (a) DSase immobilization to the pore of the membrane and (b) dextran production from dextransucrase in a permeation mode.

group at the 3-th in the pyranose ring. Con A was adsorbed to the produced dextran in permeation mode. The amount of produced dextran and the residence time of Con A were changed to evaluate the state of produced dextran from immobilized dextransucrase.

\section{Experimental}

\subsection{DSase immobilization and dextran production throughout the membrane}

DSase solution $(0.1 \mathrm{U} / \mathrm{mL}, 0.01 \mathrm{M}$ acetate buffer, $\mathrm{pH} 5.5)$ was permeated through the SPG porous hollow-fiber membrane (I.D. $4 \mathrm{~mm}$, O. D. $5 \mathrm{~mm}$, pore diameter $2000 \mathrm{~nm}$ ) with an effective length of $1.5 \mathrm{~cm}$ at a rate of $60 \mathrm{~mL} / \mathrm{h}$ at ambient temperature. The effluent penetrating the outside surface of the SPG membrane was continuously collected, and the activity of DSase in the effluent was determined. An activity of $1 \mathrm{U}$ was defined as the amount of enzyme required to produce $1 \mu \mathrm{mol}$ of fructose in one minute.

Sucrose solution ( $0.01 \mathrm{M}$ acetate buffer, $\mathrm{pH} 5.5)$ was permeated radially outward from the inner surface of the DSase-immobilized SPG membrane at $60 \mathrm{~mL} / \mathrm{h}$. The effluent was continuously collected and the fructose concentration produced by DSase was determined using the Somogyi-Nelson method [8].

\subsection{Permeation of concanavalin A solution through the membrane}

Con A solution $(0.1 \mathrm{~g} / \mathrm{L})$ dissolved in $10 \mathrm{mM}$ acetate buffer at $\mathrm{pH} 5.5$ was permeated through the membrane at $5 \mathrm{~mL} / \mathrm{h}$. The effluent was collected and the concentration of Con A in it was determined by UV absorbance at a wavelength of $280 \mathrm{~nm}$.

\section{Results and Discussion}

\subsection{Dextran immobilization and dextran production in the membrane}

DSase solution was permeated through the SPG membrane. SPG was used as a DSase support because SPG can capture DSase at a high density to form the dextran from the active site. When the DEV, dimensionless 


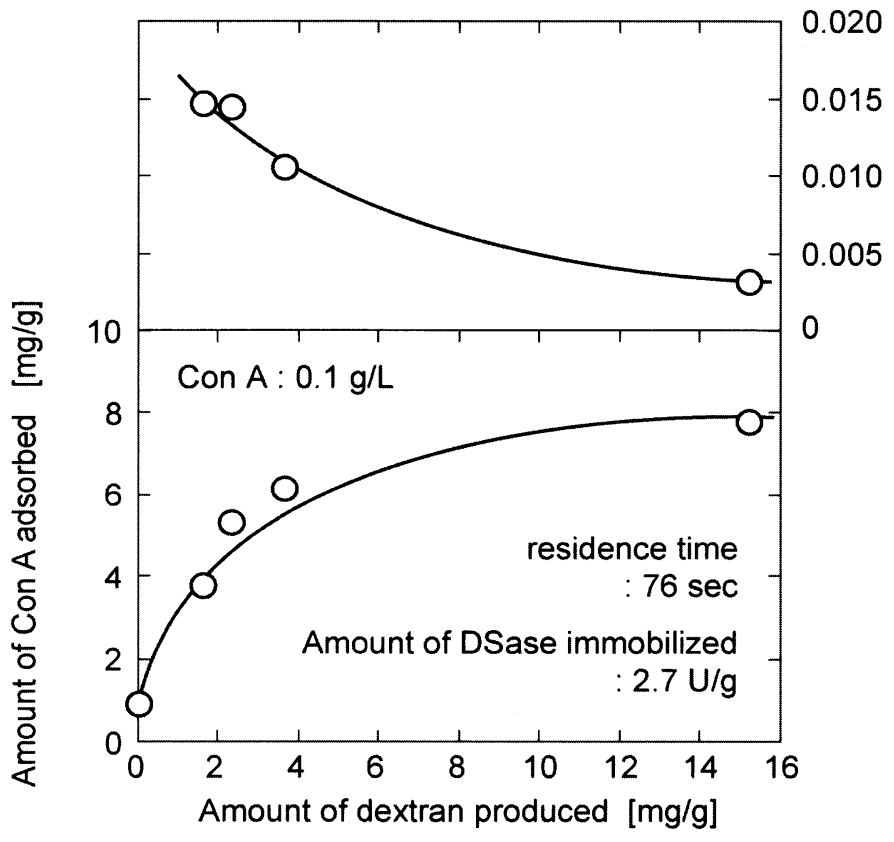

Fig. 2 Con A adsorption as a function of the amount of dextran produced from dextransucrase.

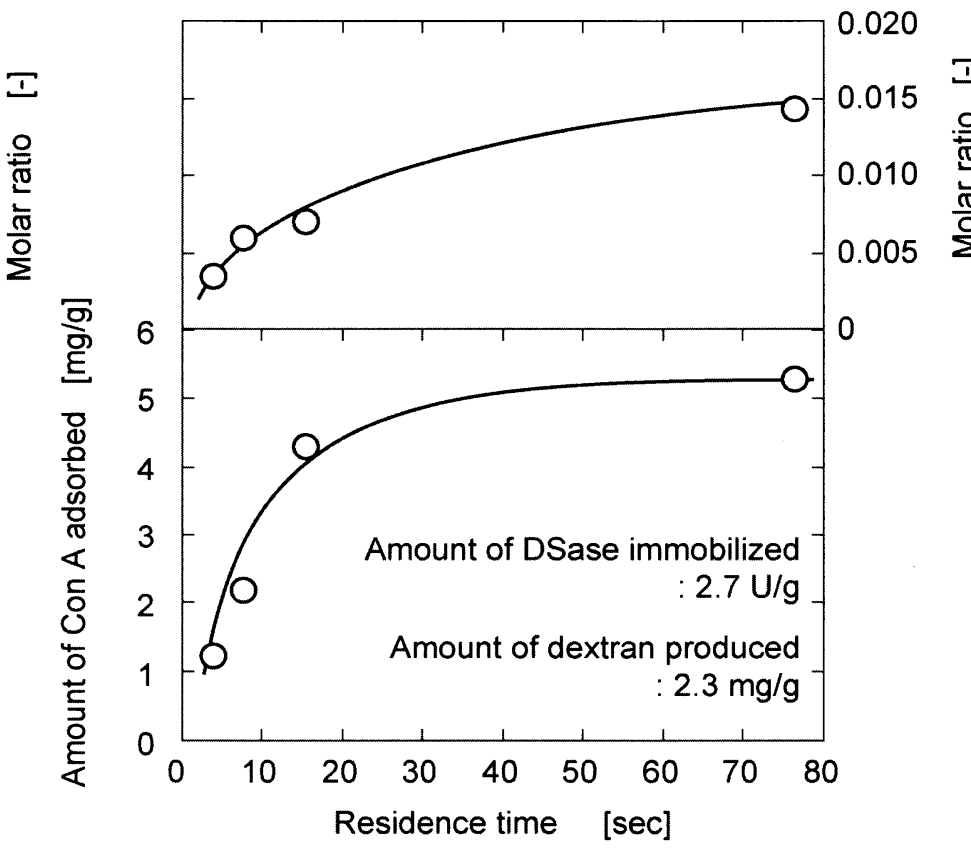

Fig. 3 Con $\mathrm{A}$ adsorption as a function of a residence time of sucrose in the membrane.

effluent volume, defined as the permeated DSase solution volume divided by the membrane volume, reached 1000 , $1.4 \mathrm{U}$ per gram of SPG membrane was immobilized (Fig. 1 (a)). No permeation pressure loss was observed, indicating that immobilization of DSase on the surface had a negligible effect on the occupation of the membrane pore. DSase immobilization occurred via a hydrophilic interaction with the silanol group of the pore surface. The amount of dextran produced together with the pressure loss during permeation of sucrose solution through the DSase-immobilized SPG membrane is shown in Fig. 1 (b). With increasing permeation of the sucrose solution, the amount of dextran produced increased linearly. The pressure loss also increased, indicating that the dextran produced occupied the pore of the membrane.

\subsection{The effect of the amount of produced dextran on the concavavalin A adsorption}

Con A solution was permeated through the DSase-immobilized membrane (Fig. 2). The amount of DSase immobilized and the residence time of Con A was set at $2.7 \mathrm{U} / \mathrm{g}$ and 76 seconds, respectively. The molar ratio of binding Con $\mathrm{A}$ was defined by the moles of the adsorbed Con A divided by the moles of produced glucose unit of dextran. The amount of Con A adsorbed increased gradually with increasing the amount of produced dextran, whereas the molar ratio of binding Con A decreased. The molar ratio was approximately 0.01, demonstrating that the loss of the dextran for Con A adsorption occurred. That resulted from the diffusional mass-transfer resistance of Con A and the high density of produced dextran.

\subsection{The effect of Con $A$ residence time on the adsorption}

The residence time of Con A was changed with the permeation rate of Con A solution to evaluate the adsorption of Con A to produced dextran as shown in Fig. 3. The amount of Con A adsorbed and the molar ratio increased with increasing the residence time. The adsorption process was mainly classified into the three steps: 1) permeation of Con A to the dextran, 2) diffusion into the dextran, and 3) adsorption reaction at the dextran. 
The adsorption of Con A to dextran quickly occurred compared with the diffusion step. The rate-determining step of Con A was the diffusional step through the produced dextran layer. To overcome the rate-determining step, the density of the produced dextran should be regulated. The density of dextran related to the density of DSase. The immobilization method of DSase should be controlled to fabricate the sophisticated dextran for lectin adsorption.

\section{References}

1) M. Naessens, A. Cerdobbel, W. Soetaert, and E. J. Vandamme, J. Chem. Technol. Biotechnol., 80, 845-860 (2005).

2) R. Terg, C. D. Migiez, L. Castro, H. Araldi, S. Dominguez, and M. Rubio, J. Hepatol., 25, 329-333 (1996).

3) B. Porch, and L. O. Sundelot, J. Chromatogr. A, 669, 21-30 (1994).

4) C. Rimington, and R. V. Belcher, J. Chromatogr., 28, 112-117 (1967).

5) M. Hoorfer, M. A. Kurz, Z. Policova, M. L. Hair, and A. W. Neumann, Langmuir, 22, 52-56 (2006).

6) D. Miksa, E. R. Irish, D. Chen, R. J. Composto, and D. M. Eckmann, Biomacromolecules, 7, 557-564 (2006).

7) M. Hasegawa, T. Kaku, M. Kuroda, N. Ise, and H. Kitano, Biotechnol. Appl. Biochem., 16, 40-47 (1992).

8) N. Nelson, J. Biol. Chem., 153, 375-380 (1944). 